This is the "Authors Accepted Manuscript" of an article finally published in: Journal of Crystal

Growth, Volume 310, Issue 23, 2008, Pages 4715-4719. DOI: 10.1016/j.jcrysgro.2008.07.038

\title{
Tailor-made Precursors for the Deposition of Sb-containing Materials by
}

\section{MOCVD Process}

Daniella Schuchmann, ${ }^{\mathrm{a}}$ Marcel Schwartz, ${ }^{\mathrm{a}}$ Stephan Schulz, ${ }^{\text {a* }}$ Andreas Seemayer, ${ }^{\mathrm{b}}$ Klaus Wandelt ${ }^{\mathrm{b}}$

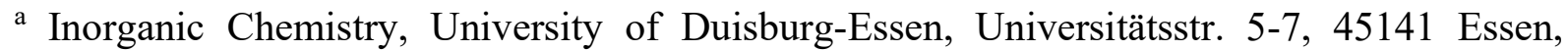
Germany; Phone: + 49 201-1834635; Fax: + 49 201-1833830; e-mail: stephan.schulz@unidue.de

${ }^{\mathrm{b}}$ Physical Chemistry, University of Bonn; Wegelerstr. 12, 53115 Bonn, Germany.

\begin{abstract}
Crystalline GaSb films were deposited using tailor-made single source precursors $[t$ $\left.\mathrm{Bu}_{2} \mathrm{GaSbEt}_{2}\right]$ in a specifically designed MOCVD reactor under $\mathrm{HV}$ conditions at low temperatures. In addition, tetraethyldistibine $\mathrm{Sb}_{2} \mathrm{Et}_{4}$ has been successfully used as precursor for the deposition of crystalline antimony films at low temperatures.
\end{abstract}

Keywords:A1. single source precursor, A3. MOCVD, B1. antimony, B1. gallium antimonide PACS: 81.05.Ea, 81.15.Gh, 81.05.Bx 


\section{Introduction}

In the last decade antimony-containing materials arouse significant interest for technical applications in electronic and optoelectronic devices. Group 13-antimonides $\mathrm{MSb}(\mathrm{M}=\mathrm{Al}$, $\mathrm{Ga}, \mathrm{In})$ are of particular interest due to their small band gaps and high electron mobilities.[1] In addition, thermoelectric materials such as $\mathrm{Sb}_{2} \mathrm{Te}_{3}, \mathrm{ZnSb}, \mathrm{Zn}_{4} \mathrm{Sb}_{3}$ and $\mathrm{CoSb}_{3}$ have been in the focus of interest for many years.[2] Unfortunately, the deposition of thin films of these materials by MOCVD process suffers from several problems, many of them directly related to the lack of suitable precursors.[3] $\mathrm{SbH}_{3}$ would be an ideal precursor for MOCVD process due to the absence of any organic substituents, which are potential sources for carbon contaminations in the resulting material films, but it is thermally too unstable.[4] The same holds for primary stibines of the types $\mathrm{RSbH}_{2}$ and $\mathrm{R}_{2} \mathrm{SbH}(\mathrm{R}=\mathrm{Me}, \mathrm{Et})$. Therefore, trialkylstibines $\mathrm{SbR}_{3}(\mathrm{R}=\mathrm{Me}, \mathrm{Et})$ [5] and trisaminostibines $\mathrm{Sb}\left(\mathrm{NR}_{2}\right)_{3}$ [6] have been established as $\mathrm{Sb}$ sources for the deposition of thin films of binary and ternary antimonides. Unfortunately, many antimonides have low melting points (e.g. InSb $525{ }^{\circ} \mathrm{C}$ ), which limits their growth using thermally stable trialkylstibines. These typically require high substrate temperatures $\left(>450{ }^{\circ} \mathrm{C}\right)$ to ensure their complete decomposition. As a consequence, Sbcontaining material films are often grown in the kinetically controlled regime, which favors carbon contamination of the resulting films due to an incomplete decomposition of the precursors.[7] Finally, the low vapor pressure of elemental antimony requires a precise control of the $\mathrm{SbR}_{3}: \mathrm{GaR}_{3}$ (V:III) molar ratio less or near unity in order to avoid the deposition of an excess of elemental antimony.[8]

The as-described problems have led to an increased search for alternate precursors, focusing on two different general approaches: synthesis of simple stibines $\mathrm{SbR}_{3}$ containing different organic substituents (alkyl, aryl, amino groups) and development of so-called single source precursors such as Lewis acid-base adducts $\mathrm{R}_{3} \mathrm{M}-\mathrm{ER}_{3}$ or heterocycles $\left[\mathrm{R}_{2} \mathrm{MER}{ }_{2}\right]_{\mathrm{x}}$, which contain the elements of the desired material connected by a stable chemical bond pre-formed 
in a single molecule.[9] As-described single source precursor have been shown to be reaction intermediates in classical MOCVD reactions. They exhibit lower metal-carbon bond energies compared to group 13 and group 15 trialkyls, allowing lower decomposition temperatures, are less sensitive toward air and moisture and contain the elements of the desired material in the correct stoichiometry. Unfortunately, the vapor pressures of these precursors, which are typically high melting solids, are significantly lower compared to liquid organometallics used in traditional "two-source" MOCVD reactions. Completely alkyl-substituted heterocycles of the type $\left[\mathrm{R}_{2} \mathrm{MSbR}_{2}\right]_{\mathrm{x}}(\mathrm{M}=\mathrm{Ga}$, In) can be prepared by a novel reaction pathway established in our group in the past, the so-called distibine cleavage reactions. Distibines $\mathrm{Sb}_{2} \mathrm{R}_{4}(\mathrm{R}=\mathrm{Me}, \mathrm{Et}$, $n$-Pr, $i$ - $\mathrm{Pr})$ were found to react with trialkylgallanes and -indanes $\mathrm{MR}_{3}^{\prime}(\mathrm{M}=\mathrm{Ga}$, In) with formation of the corresponding Lewis acid-base adduct $\left[\mathrm{R}_{3}^{\prime} \mathrm{M}\right]_{\times}\left[\mathrm{Sb}_{2} \mathrm{R}_{4}\right]$, which then consequently undergoes $\mathrm{Sb}-\mathrm{Sb}$ bond cleavage reaction with subsequent formation of the fouror six-membered heterocycle $\left[\mathrm{R}_{2} \mathrm{MSbR}_{2}\right]_{\mathrm{x}} \cdot[10]$

We became interested in the synthesis of novel single source and dual source precursors and report herein on deposition studies using the four-membered heterocycle $\left[t-\mathrm{Bu}_{2} \mathrm{GaSbEt}_{2}\right]_{2}$ as a single source precursor as well as tetraethyldistibine $\mathrm{Sb}_{2} \mathrm{Et}_{4}$ as a promising $\mathrm{Sb}$ source for the deposition of antimony-containing material films at low temperatures.

\section{Experimental}

All manipulations with metalorganic compounds were performed in a glovebox under $\mathrm{N}_{2}$ atmosphere. $\mathrm{Sb}_{2} \mathrm{Et}_{4}[11]$ and $\left[t-\mathrm{Bu}_{2} \mathrm{GaSbEt}_{2}\right]_{2}[10 \mathrm{a}]$ were prepared by literature methods.

MOCVD Experiments. GaSb films were deposited on $\mathrm{Si}(100)$ substrates, which were previously degreased with isopropanol, treated with hydrofluoric acid and heated to $500{ }^{\circ} \mathrm{C}$ at $10^{-6}$ mbar for 1 hour in the reactor. The precursor $(0.2 \mathrm{~g})$ was loaded into a glass tube which was then attached to the MOCVD-apparatus. After deposition, the system was cooled to room temperature under vacuum. 
X-ray diffraction (XRD) patterns of the resulting GaSb films were recorded on a Philips1050 diffractometer with AFM secondary monochromator using $\mathrm{Cu} \mathrm{K}_{\alpha}$ radiation. Scanning electron microscopy studies (SEM) were performed using a Philips XL20 (W-filament) equipped with an energy dispersive X-ray spectroscopy (EDX) device (Noran Voyager, Si(Li)). Sb-L and Ga-K lines were used for quantification of the EDX-data and the $\mathrm{Sb} / \mathrm{Ga}$ ratio was determined using the "Metal-Thin-Foil-Method" with $k$-factors (Cliff-Lorrimer method) yielding from calibration of the EDX-system with certified GaSb from Aldrich chemical company. The samples were prepared on perforated carbon foils without further grinding. Atomic force microscopy (AFM) measurements were performed with a Pico SPM I (Molecular Imaging Corp., Santa Barbara, CA) using a BS-Cont Al cantilever from Budgetsensor with a force constant of $0.2 \mathrm{~N} / \mathrm{m}$. All AFM measurements were made under ambient conditions.

\section{Results and Discussion}

The HV-MOCVD studies were performed using the four-membered, crystalline heterocycle $\left[t-\mathrm{Bu}_{2} \mathrm{GaSbEt}_{2}\right]_{2}$. This precursor was chosen due to its expected capability to undergo clean $\beta$-hydride elimination reactions, which are known to proceed at relatively low temperatures and typically reduce the carbon contamination. In addition, $\left[t-\mathrm{Bu}_{2} \mathrm{GaSbEt}_{2}\right]_{2}$ sublimes without decomposition at $120{ }^{\circ} \mathrm{C}$ and $10^{-5}$ mbar. Preliminary studies demonstrated its capability to serve as single source precursor for the deposition of GaSb films.[12] However, its low vapor pressure and air- and moisture-sensitivity required the development of a new reactor system, which is described herein. The home-made reactor has two independent heaters for the vaporizer and the substrate heater. The distance of the substrate heater to the precursor line can be varied from 1 to $8 \mathrm{~cm}$ and the substrate to precursor line orientation from $90^{\circ}$ (orthogonal orientation) to $180^{\circ}$ (so called in-line orientation). The new reactor allows to work under HV-conditions up to $10^{-6}$ mbar. The reactor is equipped with a mass flow controller to allow a constant gas flow and constant precursor concentrations in the gas phase. 
In addition, the driving rod allows the handling of the precursor in an Ar-filled glovebox and the transport into the reactor under inert conditions.

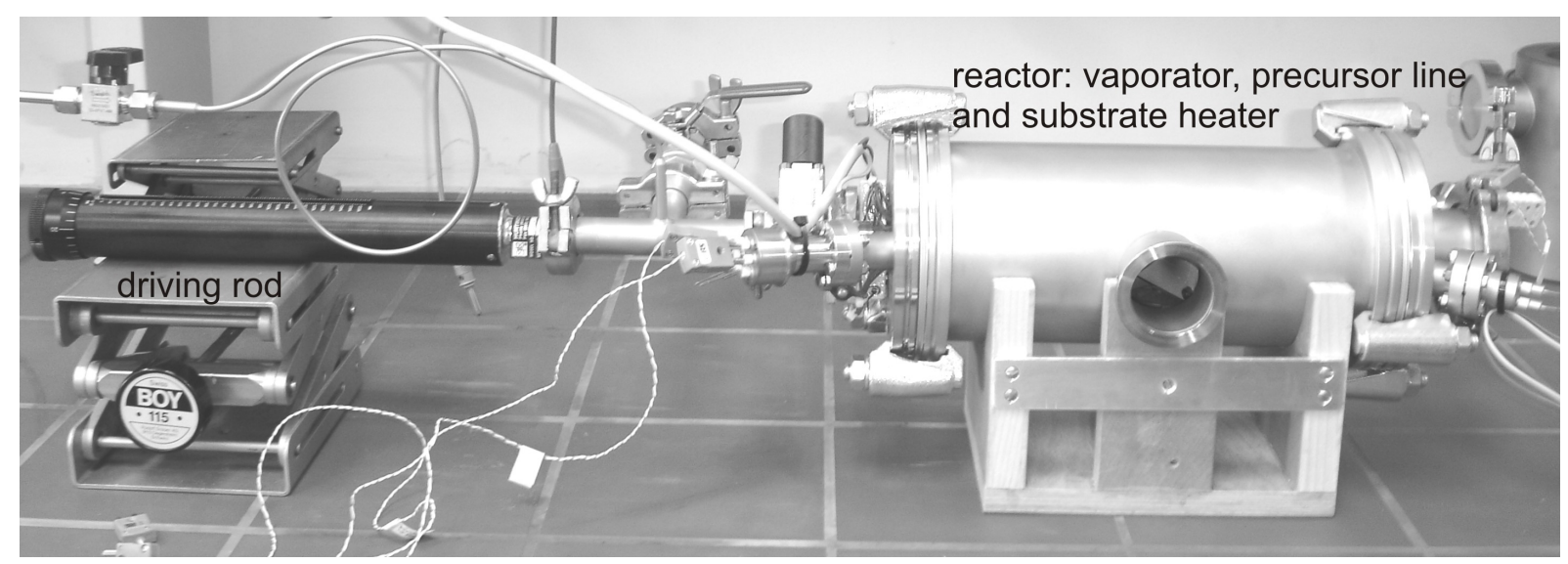

Fig.1. Photograph of the HV-MOCVD reactor.

In order to obtain a sufficient mass flow of $\left[t-\mathrm{Bu}_{2} \mathrm{GaSbEt}_{2}\right]_{2}$ and to prevent its condensation, both the evaporator and the precursor pipe were heated to $120{ }^{\circ} \mathrm{C}$. Detailed studies with different substrate temperatures $\left(350-550{ }^{\circ} \mathrm{C}\right)$ and different orientations of the substrate to the precursor flow direction $\left(90^{\circ}-160^{\circ}\right)$ were performed. Both parameters were found to be crucial for the deposition of high-quality, crystalline GaSb films on $\mathrm{Si}(100)$ substrates, with the best results obtained at substrate temperatures between 425 and $450{ }^{\circ} \mathrm{C}$ and a substrate orientation of $120^{\circ}$. Under these conditions, dense and crystalline GaSb films were grown with growth rates of $2 \mu \mathrm{m} / \mathrm{h}$. The roughness of the resulting films was as low as $40 \mathrm{~nm}$ as demonstrated by AFM.
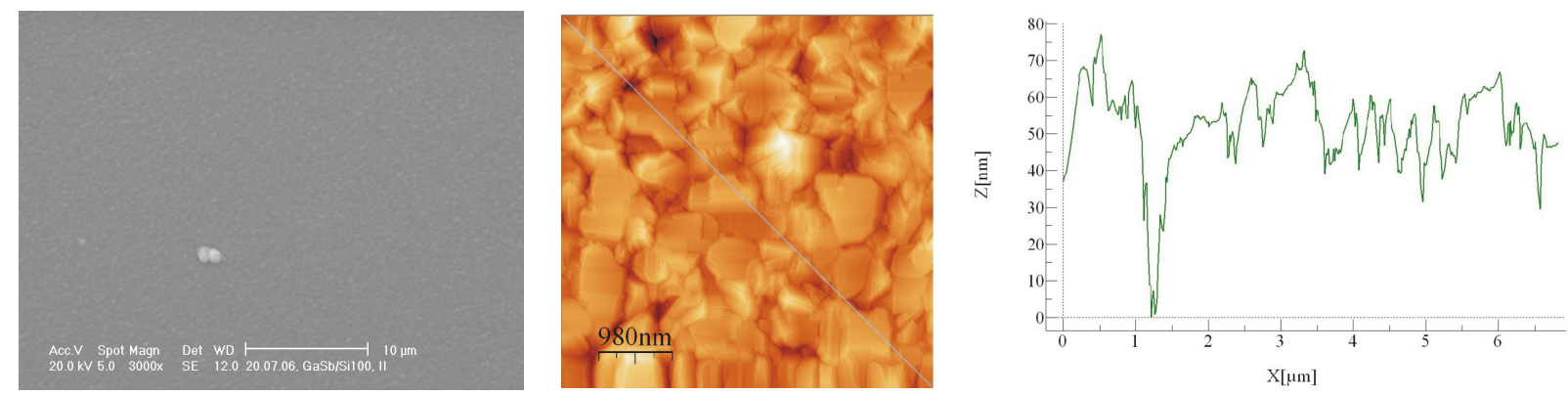

Fig.2. SEM (A, scale bar $10 \mu \mathrm{m})$ and AFM photographs (B, scale bar $980 \mathrm{~nm}$ ) of a GaSb film deposited on Sil00 at $450^{\circ} \mathrm{C}$ at $4 \times 10^{-6} \mathrm{mbar}$

These results are significant improvements compared to those obtained with the reactor previously described.[12] Using this reactor, substrate temperatures between 450 and $550{ }^{\circ} \mathrm{C}$ 
were required and the surface of the resulting GaSb films was significantly rougher (about $200 \mathrm{~nm}$ ). In addition, the growth rates were much slower (about $1 \mu \mathrm{m} / \mathrm{h}$ ). Small carbon and oxygen concentrations were detected by Auger spectroscopy (fig. 3). However, sputtering experiments clearly proved these contaminations to be only present at the surface due to surface oxidation reactions and adsorbed precursor fragments.

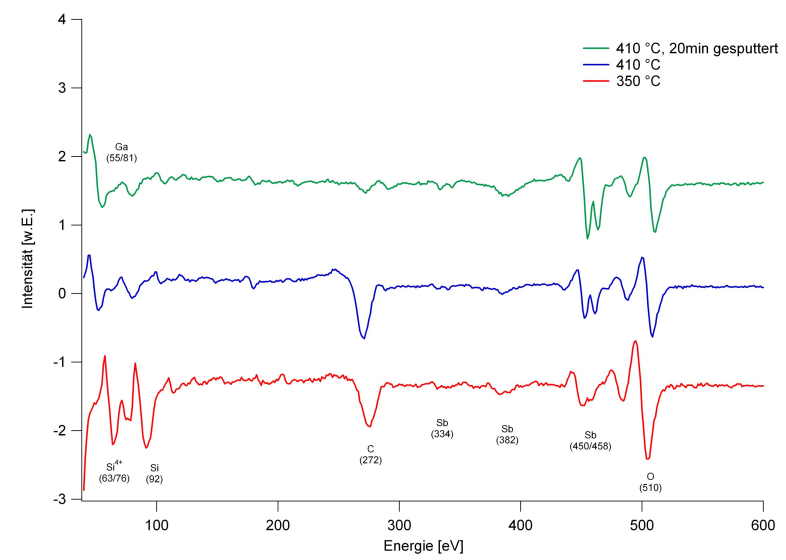

Fig. 3 AES photographs of GaSb films deposited on Sil00 at 350 and $410^{\circ} \mathrm{C}$

The substrate has a crucial influence on the quality of the resulting GaSb films as was demonstrated using $\mathrm{Si}(100)$ (substrate I), partially oxidized $\mathrm{Si}(100)$ (100 nm $\mathrm{SiO}_{2}$ surface; substrate II)) and glass (substrate III) at the same deposition conditions $\left(10^{-5} \mathrm{mbar}, 450{ }^{\circ} \mathrm{C}\right)$.

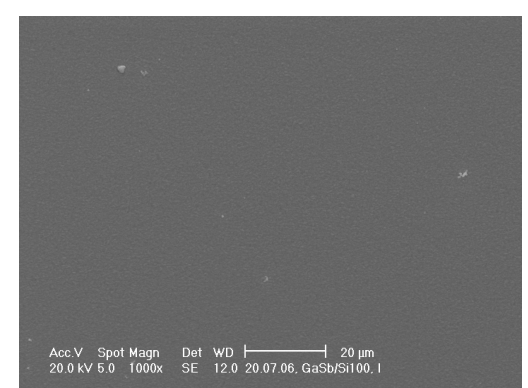

A

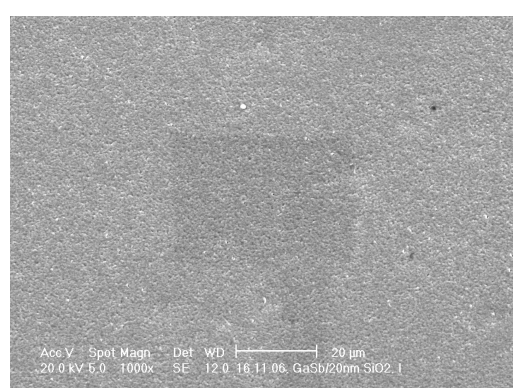

B

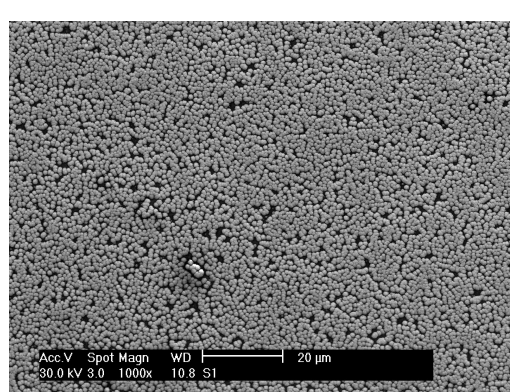

C

Fig. 4. SEM images of GaSb films deposited on substrate I (A), II (B) and III (C) (scale bars $20 \mu \mathrm{m})$.

The films on $\operatorname{Si}(100)$ substrates are very dense, whereas on glass substrates island growth was observed and the population density is very low. The density of GaSb films deposited on partially oxidized $\operatorname{Si}(100)$ was found to be in between those observed for $\operatorname{Si}(100)$ and glass substrates. In addition, films obtained on glass and partially oxidized $\mathrm{Si}(100)$ substrates contain large amounts of amorphous $\mathrm{Ga}_{2} \mathrm{O}_{3}$. The $\mathrm{Ga}$ content was found to vary from $60-65 \%$, 
clearly proving the formation of Ga-rich material films. Obviously, the oxophilic Ga atoms deposited on the surface react with the $\mathrm{O}$ atoms of the substrate material resulting in the formation of $\mathrm{Ga}_{2} \mathrm{O}_{3}$, whose formation energy is higher compared to that of $\mathrm{GaSb}$. However, XRD experiments only showed diffraction patterns of sphalerit-type GaSb. The pattern is drawn in logarithmic scale, otherwise only the strong Si reflex at $69^{\circ} 2$ theta would be visible. Characteristic reflexes due to sphalerite-type GaSb clearly prove the formation of crystalline GaSb films. These reflexes match with JCPDS-File 070215 (black). In addition, peaks due to $\mathrm{Si}$ (substrate, blue) and $\mathrm{Al}$ (sample holder, green) are observable.

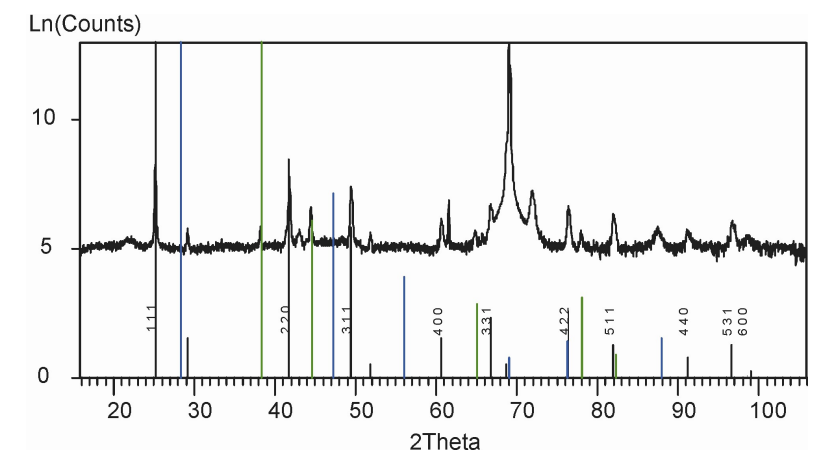

Fig. 5. XRD spectrum of a GaSb film deposited at $400{ }^{\circ} \mathrm{C}$ on substrate II.

Even though high quality GaSb films were successfully deposited on $\mathrm{Si}(100)$ using asdescribed single source precursors, the problems related to the use of these specific precursors forced us also to look for new precursors applicable in dual source deposition studies. We became interested in distibines $\mathrm{Sb}_{2} \mathrm{R}_{4}$ such as tetramethyl- and tetraethyldistibine, since these molecules tend to disproportionate in solution at relatively low temperature into elemental antimony and $\mathrm{SbR}_{3}$. In contrast, $\mathrm{SbMe}_{3}$ and $\mathrm{SbEt}_{3}$ show much higher thermal stability (decomposition temperature $>400{ }^{\circ} \mathrm{C}$ ).

Mass spectroscopic studies clearly demonstrated $\mathrm{Sb}_{2} \mathrm{Me}_{4}$ to be stable up to $300{ }^{\circ} \mathrm{C}$, whereas it is completely decomposed at $400{ }^{\circ} \mathrm{C}$. Only signals due to the presence of $\mathrm{SbMe}_{2}, \mathrm{SbMe}_{3}$ and SbMe were detected. At $750{ }^{\circ} \mathrm{C} \mathrm{C}_{4-}, \mathrm{C}_{3}-, \mathrm{C}_{2}$ - and $\mathrm{C}_{1}$-species were detected as a result of complete thermolysis. In remarkable contrast, $\mathrm{Sb}_{2} \mathrm{Et}_{4}$ is only stable up to $100{ }^{\circ} \mathrm{C}$. At higher temperatures signals due to the formation of $\mathrm{SbEt}_{3}$ were observed, whose intensity reaches a 
maximum between $200-250{ }^{\circ} \mathrm{C}$. At $250{ }^{\circ} \mathrm{C}, \mathrm{Sb}_{2} \mathrm{Et}_{4}$ is completely decomposed. Moreover, no production of any hydrocarbon was observed, indicating a clean decomposition pathway, whereas hydrocarbons were detected above $250{ }^{\circ} \mathrm{C}$.[13] Based on these promising initial studies we performed MOCVD studies using a simple hot-wall reactor at a working pressure of $10^{-2}$ mbar and substrate temperatures between 200 and $300{ }^{\circ} \mathrm{C}$ on untreated $\mathrm{Si}(100)$ substrates. The distibine was heated to $40{ }^{\circ} \mathrm{C}$ in order to provide a sufficient mass flow.

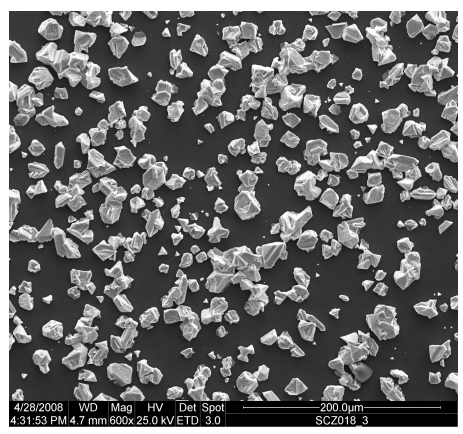

A

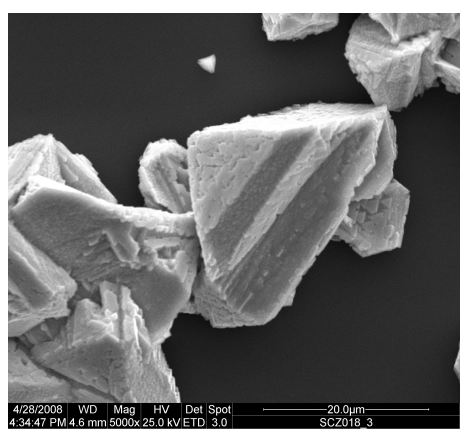

D

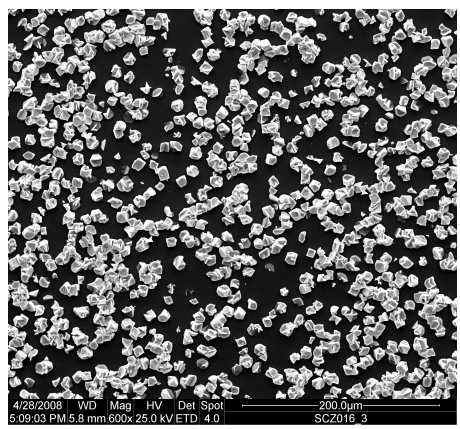

B

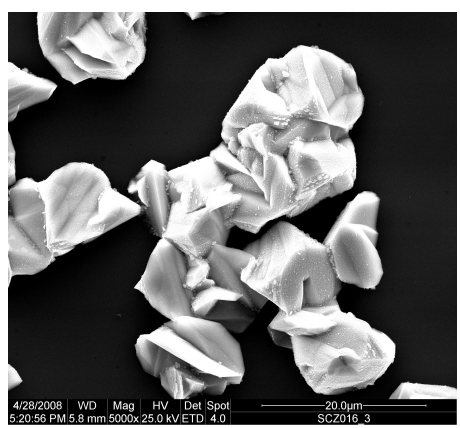

$\mathbf{E}$

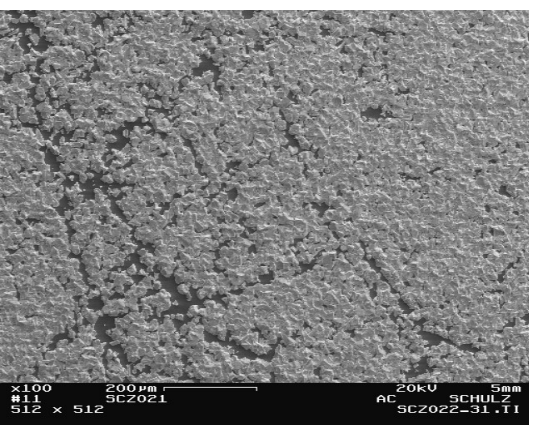

C

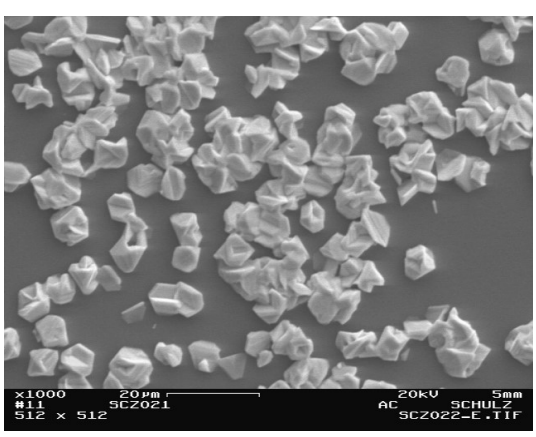

$\mathbf{F}$

Fig. 6. SEM images of Sb films deposited at $210(A, D), 250(B, E)$ and $300{ }^{\circ} C(C, F)$ on Si(100) substrates using the hot-wall reactor (scale bars $200 \mu \mathrm{m}(A-C), 20 \mu \mathrm{m}(D-F)$ ).

Figure 6 display the SEM photographs of the resulting Sb films deposited at 210, 250 and 300 ${ }^{\circ} \mathrm{C}$, respectively. Within this temperature range the density of the films steadily increases with increasing temperature as is typical for a kinetically controlled film growth. XRD studies of the resulting films clearly prove the deposition of crystalline Sb films. The reflexes observed match with those of crystalline Sb (JCPDS-File 010802 (blue)). EDX spectra show that the contamination with carbon is less than $2 \%$ even under these non-optimized deposition conditions. These results perfectly agree with those obtained from the mass spectroscopic 
studies, clearly proving $\mathrm{Sb}_{2} \mathrm{Et}_{4}$ to undergo a clean decomposition pathway with subsequent formation of elemental $\mathrm{Sb}$ and $\mathrm{SbEt}_{3}$ at very low temperatures.

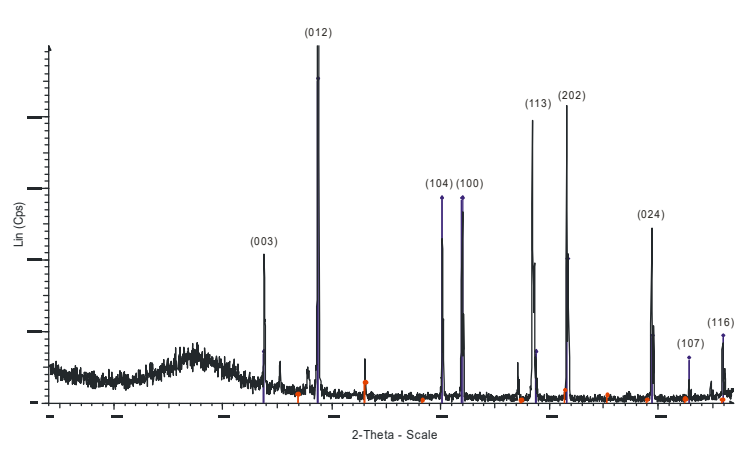

A

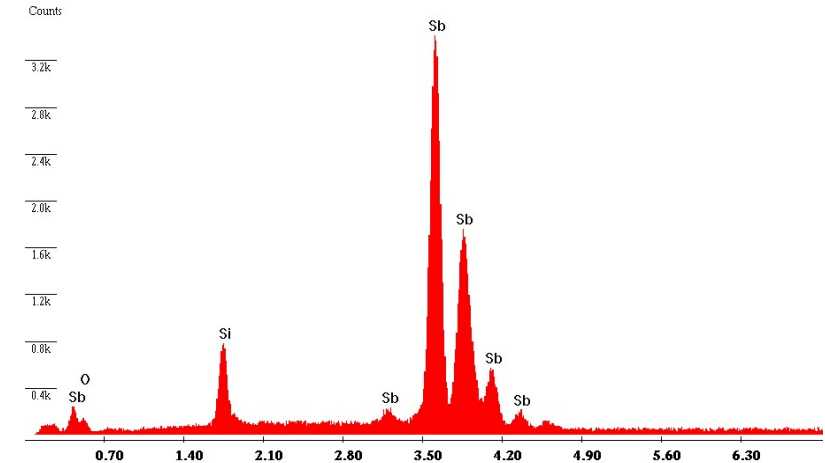

B

Fig. 7. XRD plot of Sb film on Si(100) at $300{ }^{\circ} \mathrm{C}$ (A), blue lines: Sb (JCPDS: 010802); red lines: Si substrate reflexes and EDX spectrum of $\mathrm{Sb}$ film on $\mathrm{Si}(100)$ at $250{ }^{\circ} \mathrm{C}(\mathrm{B})$.

\section{Conclusions}

The single source precursor $\left[t-\mathrm{Bu}_{2} \mathrm{GaSbEt}_{2}\right]_{2}$ was successfully used for the deposition of crystalline GaSb films in a specifically designed cold-wall MOCVD reactor under HV conditions. The density and elemental composition of the resulting material film was found to be strongly dependent on the substrate material, the substrate temperature and the orientation of the substrate to the precursor line. The best results were obtained at substrate temperatures between 425 and $450{ }^{\circ} \mathrm{C}$ and a substrate orientation of $120^{\circ}$. The quality of the resulting film strongly depends on the substrate material. On $\mathrm{Si}(100)$ substrates, very dense crystalline $\mathrm{GaSb}$ films were grown with a growth rate of $2 \mu \mathrm{m} / \mathrm{h}$. In addition, preliminary MOCVD studies with the distibine $\mathrm{Sb}_{2} \mathrm{Et}_{4}$ show very promising. Deposition studies at low temperatures between $200{ }^{\circ} \mathrm{C}$ and $300{ }^{\circ} \mathrm{C}$ show a clean decomposition process resulting in the formation of elemental $\mathrm{Sb}$ and $\mathrm{SbEt}_{3}$. These results correspond to mass spectrometric studies performed at temperatures between 25 and $700{ }^{\circ} \mathrm{C}$. According to these results, $\mathrm{Sb}_{2} \mathrm{Et}_{4}$ seems to be a very attractive low-temperature source for the classical dual source approach for the deposition of antimony-containing material films. 
Acknowledgment. Funding by the priority program SPP 1119 of the Deutsche Forschungsgemeinschaft (DFG) and the Fonds der Chemischen Industrie (fellowship for D.S.) is gratefully acknowledged.

\section{References}

[1] J. M. McChesney, J. Haigh, I. M. Dharmadasa, D. J. Mowthorpe, Opt. Mater. 6 (1996), 63.

[2] a) A. Majumdar, Science 303 (2004) 777; b) R. Venkatasubramanian, E. Siivola, T.

Colpitts, B. O'Quinn, Nature 413 (2001) 597; c) S. Schlecht, C. Erk, M. Yosef, Inorg. Chem 45 (2006) 1693.

[3] a) A. Aardvark, N. J. Mason, P. J. Walker, Prog. Crystal Growth and Charact. 35 (1997) 207; b) R. M. Biefeld, Mater. Sci. Eng. R. 36 (2002) 105.

[4] a) M. A. Todd, G. Bandari, T. H. Baum, Chem. Mater. 11 (1999) 547; b) B. C. Harrison, E. H. Tompkins, Inorg. Chem. 1 (1962) 951; c) O. Sugiura, H. Kameda, K. Shiina, M. Matsumura, J. Electron. Mater. 17 (1988) 11.

[5] See for instance: a) R. M. Biefeld, A. A. Allerman, S. R. Kurtz, J. Cryst. Growth 174 (1997) 593; b) C. W. Wang, M. C. Finn, S. Salim, K. F. Jensen, A. C. Jones, Appl. Phys. Lett. 67 (1995) 1384; c) C. W. Wang, K. F. Jensen, A. C. Jones, H. K. Choi, Appl. Phys. Lett. 68 (1996) 400; d) R. M. Biefeld, A. A. Allerman, M. W. Pelczynski, Appl. Phys. Lett. 68 (1996) 932.

[6] J. Shin, A. Verma, G. B. Stringfellow, R. W. Gedridge, J. Cryst. Growth 143 (1994) 15.

[7] a) C. A. Wang, S. Salim, K. F. Jensen, A. C. Jones, J. Crystal Growth 170 (1997) 55; b) J. S. Ford, F. P. Howard, G. J. Davies, J. Cryst. Growth 188 (1998) 159.

[8] a) J. Shin, A. Verma, G. B. Stringfellow, R.W. Gedridge Jr., J. Crystal Growth 151 (1995) 1; b) A. Subekti, E.M. Goldys, M. J. Paterson, K. Drozdowicz-Tomsia, T. L. Tansley, J. 
Mater. Res. 14 (1999) 1238; c) A. Subekti, E. M. Goldys, T. L. Tansley, J. Phys. Chem. Sol. $61(2000) 537$.

[9] a) A. H. Cowley, R. A. Jones, Angew. Chem. Int. Ed. 28 (1989) 1208; b) A. C. Jones, Chem. Soc. Rev. (1997) 101; c) P. O'Brien, S. Haggata, Adv. Mater. Opt. Electron. 5 (1995) 117.

[10] a) A. Kuczkowski, S. Schulz, M. Nieger, P. Saarenketo, Organometallics 20 (2001) 2000; b) A. Kuczkowski, S. Fahrenholz, S. Schulz, M. Nieger, Organometallics 23 (2004) 3615; c) D. Schuchmann, A. Kuczkowski, S. Fahrenholz, S. Schulz, U. Flörke, Eur. J. Inorg. Chem. 7 (2007) 931.

[11] H. A. Meinema, H. F. Martens, J. G. Noltes, J. Organomet. Chem. 51 (1973), 223.

[12] S. Schulz, S. Fahrenholz, A. Kuczkowski, W. Assenmacher, A. Seemayer, K. Wandelt, Chem. Mater. 17 (2005) 1982.

[13] N. Bahlawane, F. Reilmann, S. Schulz, D. Schuchmann, K. Kohse-Höinghaus, J. Am. Soc. Mass Spectrom. (2008) in the press. 


\section{DuEPublico}

This text is made available via DuEPublico, the institutional repository of the University of Duisburg-Essen. This version may eventually differ from another version distributed by a commercial publisher.

DOI: $\quad 10.1016 /$ j.jcrysgro.2008.07.038

URN: urn:nbn:de:hbz:464-20201027-084134-2

This is the "Authors Accepted Manuscript" of an article finally published in: Journal of Crystal Growth, Volume 310, Issue 23, 2008, Pages 4715-4719. DOI: 10.1016/j.jcrysgro.2008.07.038 